\title{
Erratum to: Increased glucocerebrosidase (GBA) 2 activity in GBA1 deficient mice brains and in Gaucher leucocytes
}

\author{
Derek G. Burke • Ahad A. Rahim • Simon N. Waddington • \\ Stefan Karlsson • Ida Enquist • Kailash Bhatia • \\ Atul Mehta • Ashok Vellodi • Simon Heales
}

Published online: 26 February 2013

(C) SSIEM and Springer Science+Business Media Dordrecht 2013

\section{Erratum to: J Inherit Metab Dis}

\section{DOI 10.1007/s10545-012-9561-3}

In the original published article, we stated that we used deoxynojirimycin as an inhibitor of GBA2. This is incorrect. In fact, N-butyldeoxynojirimycin was utilised, as a GBA2 inhibitor, in this study.

The online version of the original article can be found at http://dx.doi.org/ 10.1007/s10545-012-9561-3.

D. G. Burke $\cdot$ S. Heales

Clinical \& Molecular Genetics Unit, UCL Institute of Child Health and Chemical Pathology, Great Ormond Street Hospital,

London, UK

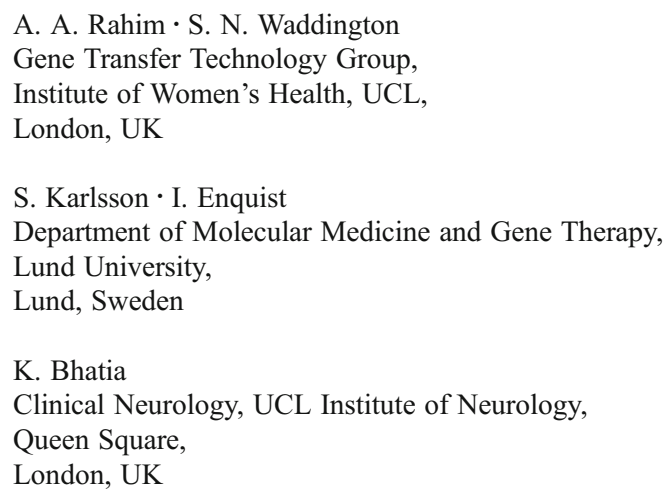

A. Mehta

Royal Free Hospital,

London, UK

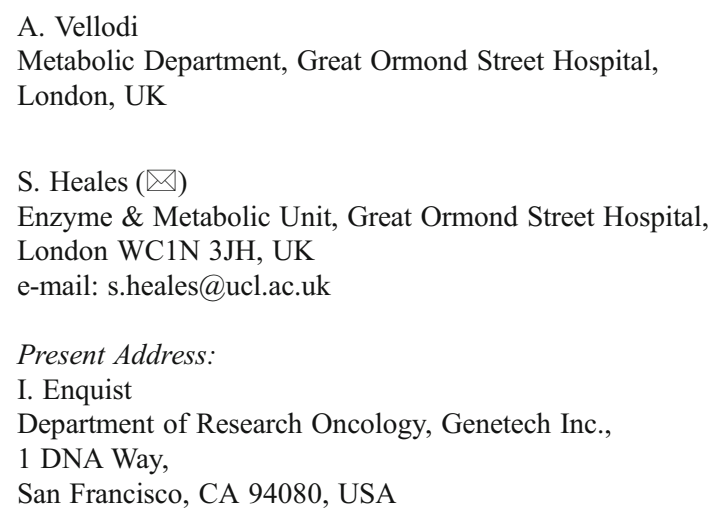

